\title{
O PROCESSO DE INOVAÇÃO TECNOLÓGICA DE EMPRESAS FORNECEDORAS ASSOCIADAS À REDE PETROGAS/SE
}

\author{
Wanusa Campos Centurión \\ Mestre em Administração pela Universidade Federal de Pernambuco - UFPE \\ Coordenadora do Curso Tec. Gestão de RH e Logística da Faculdade de Administração e Negócios de \\ Sergipe - FANESE \\ wanusa@infonet.com.br (Brasil)
}

\section{Fernando Gomes de Paiva Júnior}

Doutor em Administração pela Universidade Federal de Minas Gerais - UFMG

Professor da Universidade Federal de Pernambucov - UFPE

fernando.paivajr@gmail.com (Brasil)

\section{Jorge da Silva Correia Neto}

Doutorado em Administração pela Universidade Federal de Pernambuco - UFPE

Professor da Universidade Federal Rural de Pernambuco - UFPE

jorgecorreianeto@gmail.com (Brasil)

\section{Rosivaldo de Lima Lucena}

Doutor em Engenharia de Produção pela Universidade Federal da Paraíba - UFPB

Professor da Universidade Federal da Paraíba - UFPB

rosivaldolucena@gmail.com (Brasil)

\section{RESUMO}

A inovação tecnológica tem despertado o interesse dos gestores de micro, pequenas e grandes empresas porque é um tema contemporâneo que acelera processos sustentáveis em diversas áreas da Administração, principalmente reconhecida por governos, empresários, universidades e centros de pesquisa como indispensável na economia contemporânea. Por outro lado, o número de organizações que possuem sistemas e processos estruturados de inovação ainda representa uma minoria, uma vez que as ideias não se materializam como produtos ou serviços, e muitas ações inovadoras são isoladas, pouco efetivas e sem vínculo com os objetivos estratégicos das empresas. Como pesquisa de natureza qualitativa, o estudo descreve o processo de inovação de seis empresas fornecedoras associadas à rede PETROGAS/SE, sob a perspectiva de seus dirigentes. As entrevistas foram analisadas com suporte da análise de conteúdo e os resultados revelam que a gestão do processo de inovação está centrada no conhecimento tácito dos dirigentes, as empresas com certificação de qualidade tendem a gerir seu processo de inovação de forma mais estruturada e algumas etapas desse processo dispõem de maior aderência ao modelo de inovação discutido no estudo.

Palavras-chave: Processo de Inovação; Redes de Empresas; Petróleo e Gás. 


\section{INTRODUÇÃO}

Existem organizações que tendem a experimentar a inovação de forma episódica, única, como evento isolado e com base na sorte. Por isso, alguns estudiosos reforçam a ideia da inovação representada como um fenômeno ocasional e incidental. Por tal razão, essas empresas acabam por desperdiçar tempo e dinheiro diante da falta de planejamento e da recorrência de erros (Bessant \&Tidd, 2009).

Nesse contexto, encontram-se as micro, pequenas e médias empresas (MPME), cujas etapas do seu processo de inovação se desenvolvem sem uma sistematização adequada, inclusive em se tratando da dificuldade de se homogeneizar e comparar a inovação dessas empresas em diferentes setores econômicos, dificultando, com isso, a sua capacidade de se recuperar rapidamente de erros e falhas nos esforços de inovação (Von Oetinger, 2005, Oliveira et al, 2014).

O desafio da gestão da inovação comprometida com resultados de excelência consiste no ato de gerenciar cada fase do processo de maneira planejada e organizada para que possa ser repetido em eventos posteriores (Tidd, Bessant \&Pavitt, 2005; Desouza et al., 2009), uma vez que para ser bem sucedida a inovação requer um processo estruturado e sólido que propicie à organização a condição adequada para criar produtos e serviços competitivos em menor espaço de tempo, bem como otimizar sua participação no mercado (Tidd, Bessant \& Pavitt, 2005) e possuir maior clareza das diferenças existentes entre o desenvolvimento de tecnologia e a melhoria sistemática de produto (Caetano; Kurumoro \& Amaral, 2012).

No âmbito do processo estruturado de inovação nas empresas, o objetivo do estudo reside em descrever o processo de inovação de seis empresas fornecedoras associadas à rede PETROGAS/SE, sob a perspectiva de seus dirigentes. $\mathrm{O}$ alcance dessa finalidade facilita o entendimento a respeito do modo como elas operam suas atividades no setor de petróleo e gás $(P \& G)$ com base na experiência do Estado de Sergipe, bem como desenvolvem rotinas criativas e otimizadoras de fluxos de trabalho que se potencializam com ações inovadoras de êxito tecnologicamente reconhecido.

A considerar seu crescimento ativo, a indústria de $\mathrm{P} \& \mathrm{G}$ conta com uma das primeiras redes de petróleo e gás do Brasil, a rede PETROGAS/SE. Fundada no ano de 2003 por um grupo de 10 empresários egressos da PETROBRÁS, atualmente essa rede possui cerca de 120 empresas fornecedoras integrantes de determinados segmentos econômicos da cadeia de P\&G, envolvendo empreendimentos que contemplam os setores de serviços, indústria e comércio. Além disso, existem mais de 20 instituições de fomento distribuídas entre centros de pesquisa, instituições de ensino e

Revista de Administração e Inovação, São Paulo, v. 12, n.1, p.24-51, jan./mar. 2015. 
entidades financeiras, que também compõem essa rede de cooperação em tecnologia e negócios (Souza \& Oliveira, 2012).

De fato, a área de $P \& G$ se destaca como uma das principais forças inovadoras do Brasil na exploração de petróleo em águas profundas (Índice de Inovação Global, 2010). Ademais, a atividade é considerada pelo governo como uma das áreas prioritárias da política industrial brasileira, devido ao crescimento do número de inovações tecnológicas e do interesse nacional pela produção de $\mathrm{P} \& \mathrm{G}$, principalmente no que se refere à chamada expansão da matriz energética na área de pré-sal.

Em 2011, o Brasil alcançou o décimo segundo lugar no ranking mundial em produção de petróleo e o Estado de Sergipe é considerado o quinto maior produtor de Petróleo do Brasil, ficando atrás dos Estados do Rio de Janeiro, Espírito Santo, Rio Grande do Norte e Bahia (Anuário Estatístico Brasileiro do Petróleo, Gás Natural e Biocombustíveis, 2011). Tendo iniciado sua produção no mar em 1968 e sendo pioneiro na exploração de petróleo em águas profundas, o setor de P\&G representou 8,8\% do PIB sergipano em 2010, contabilizando um crescimento de quase $30 \%$ com relação ao ano anterior e incrementando os índices das estatísticas nacionais com forte expectativa de crescimento (SEPLAG, 2011).

Algumas MPME sergipanas da área de $P \& G$ têm alcançado reconhecimento nacional e internacional pelo seu potencial inovador e sido premiadas por suas práticas empreendedoras pelo SEBRAE/SE, fato que as torna mais competitivas no Brasil e no exterior (SEPLAG, 2011). Boa parte desse sucesso parece advir da experiência técnica de empreendedores que atuam na área e por serem considerados abalizados conhecedores das necessidades da indústria de P\&G na Região. Inclusive, algumas de suas inovações tecnológicas de produto ou de processo têm provocado mudanças no sistema de fornecimento da PETROBRÁS, antes centralizado em grandes empresas multinacionais, a exemplo de Halliburton, Baker e Schlumberger.

Ademais, as inovações geradas por essas companhias fornecedoras e lançadas nos mercados nacional e internacional são originárias de empresas detentoras de estilos diferenciados de gestão: existem aquelas que dispõem de ferramentas gerenciais com status de sistema de gestão certificado por normas de qualidade internacional e outras com formato de gestão mais rudimentar e de perfil tipicamente amador. Tais estilos de gestão podem tanto facilitar como dificultar a competitividade destas empresas e sua manutenção no mercado(Centurión, 2012).

Dessa forma, o esforço de realizar este estudo foi resultante de inquietações devido a tendências de empresas em experimentar a inovação de forma episódica e com isso traduzido na seguinte questão: como ocorre o processo de inovação de empresas fornecedoras associadas à rede PETROGAS/SE, sob a perspectiva de seus dirigentes? 


\section{REFERENCIAL TEÓRICO}

A sustentação teórica desse estudo para a temática processo de inovação está pautada nas pesquisas de Tidd, Bessant \& Pavitt (2005) e Desouza et al. (2009). Além das concepções de inovação propostas por esses autores, buscou-se uma conceituação dos temas relacionados ao processo de inovação no contexto de diferentes áreas do conhecimento. Assim, aqui são discutidas algumas considerações gerais sobre o processo inovador nas organizações, sendo também sugerido um arcabouço analítico referente ao modelo de Processo de Inovação. Esse arcabouço se justifica por se tentar suprir algumas lacunas inerentes ao modelo de processo de inovação proposto por Tidd, Bessant e Pavitt (2005), bem como por Desouza et al. (2009). Como as propostas destes teóricos são complementares, a ideia foi fazer uma junção delas, através de uma síntese integrada desses modelos, visando a uma maior efetividade e abrangência na discussão.

\subsection{Considerações gerais sobre Inovação}

A inovação é aqui reconhecida como um processo-chave presente nas organizações, associado à renovação tecnológica por se inspirar no intercâmbio de conhecimento, orientado para o aprendizado e, sobretudo, definido em torno de direção e lideranças estratégicas claras; além de se considerar a utilização de recursos que a viabilizem; estrutura e ambiente que estimulam as pessoas a explorarem sua criatividade e compartilharem seus saberes especializados, visando à promoção de mudanças e conexões proativas entre a empresa e seus stakeholders, de modo que possam contribuir para o processo de inovação (Tidd, Bessant\&Pavitt,2005).

Nos estudos desenvolvidos a respeito deprocessos inovadores são apontadas determinadas maneiras de classificá-la, porém algumas dimensões têm sido repetidamente enfatizadas, como assinala Cooper (1998). Esse autor ainda relata que, diante das diferentes facetas da inovação, ela é descrita como fenômeno multidimensional que se sobressai numa série de classificações, quais sejam: radical e incremental; de Produto ou processo; tecnológica e organizacional.

Quanto ao grau de novidade, a inovação pode ser incremental ou radical. A incremental é constituída por pequenas melhorias em produtos ou processos (Junarsin, 2009). Por outro lado, a inovação radical muda completamente a ordem, causando impacto mercadológico pela introdução de um novo produto ou processo (Tigre, 2006).

Revista de Administração e Inovação, São Paulo, v. 12, n.1, p.24-51, jan./mar. 2015. 
Outra classificação recorrente reside no ato de se definir a inovação como sendo de produto ou processo. Logo, a inovação do produto consiste no desenvolvimentoeintroduçãode novos produtos e serviços ou seu aperfeiçoamento significativo (Tidd, Bessant\&Pavitt, 2005). Já a inovação de processo se refere à modificação dos métodos de produção ou a implantação de um método novo no fornecimento do serviço, na entrega final ou nos processos organizacionais, o que abrange mudanças nas técnicas nos equipamentos ou nos softwares (OECD, 2005).

A inovação também pode ser classificada como tecnológica ou organizacional. A tecnológica é definida "pela introdução no mercado de um produto (bem ou serviço) novo ou substancialmente aprimorado. (PINTEC, 2008, p. 8). A inovação organizacional compreende a implementação de novos modelos de gestão ou de mudanças na organização do trabalho e nas relações externas à empresa (PINTEC, 2008).

\subsection{Processo de Inovação nas Organizações}

O processo de inovação compreende as atividades envolvidas na introdução, desenvolvimento e lançamento de novidades nas organizações (OECD, 2005). Os estudos de Desouza et al. (2009) evidenciam que a presença de um método de inovação estruturado e sistematizado corresponde a um primeiro sinal possível de um programa de inovação bem-sucedido; além disso, os autores reforçam que a inovação competitiva está alinhada ao planejamento estratégico da organização de forma a se contemplar e mensurar a capacidade inovativa para aperfeiçoamento da gestão dos riscos.

Existem modelos de processo destacados na literatura que explicam como se desencadeia e se organiza tal dinâmica na organização e no mercado, desvelando a forma ou os momentos em que organizações conseguem retorno de suas inovações e quando precisam inovar radical ou parcialmente seus produtos, serviços, processos e negócios (Vicenti \& Machado, 2010). Tais modelos são classificados em estáticos ou lineares, bem como dinâmicos ou não-lineares.

Nos modelos lineares, a ênfase reside no investimento em pesquisa tecnológica e existe pouca interação entre os stakeholders. Assim, Abernathy e Clark (1985) e Teece (1986) apresentam exemplos desses modelos. Já os dinâmicos possuem alto grau de interação entre os atores participantes dos processos de desenvolvimento de uma inovação. Alguns estudiosos desenvolvem estudos que ilustram esse tipo de modelo (Barbieri \& Álvares, 2003;Tidd, Bessant e Pavitt, 2005 e Desouza et al. 2009).

Revista de Administração e Inovação, São Paulo, v. 12, n.1, p.24-51, jan./mar. 2015. 
Os modelos dinâmicos de Tidd, Bessant e Pavitt (2005) e Desouza et al.(2009)se destacam por terem sido aplicados em vários tipos de organização de portes distintos, bem como pela capacidade dos autores no sentido de descreverem o processo de inovação com base nesses modelos propostos.

O modelo do processo de inovação proposto por Tidd, Bessant e Pavitt (2005), apresentado na Figura 1, é composto por quatro etapas comuns às empresas que se alimentam e são retroalimentadas pelo processo de aprendizado dinâmico, contemplando as seguintes fases: procura, seleção, implementação e aprendizagem.

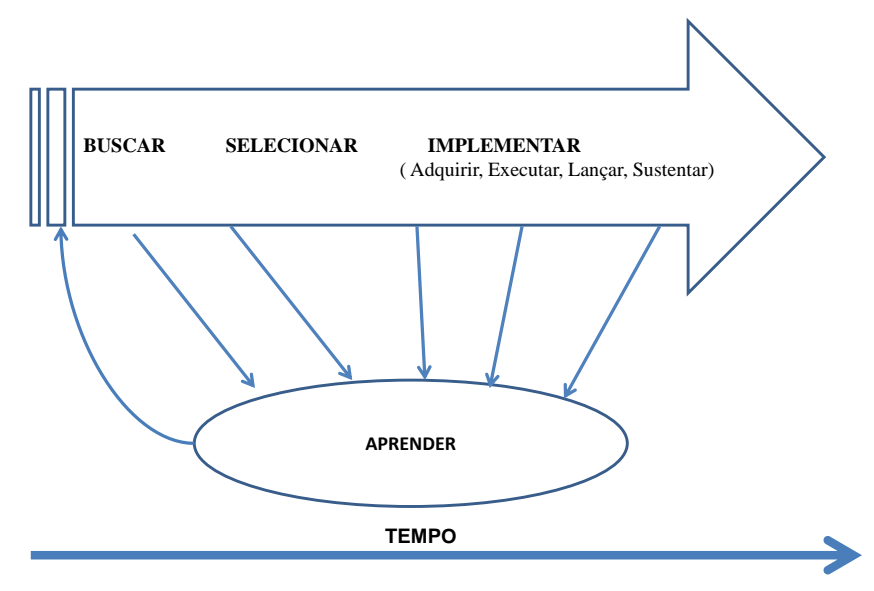

\section{Figura 1. Modelo do Processo de Inovação de Tidd, Bessant, \&Pavitt (2005)}

Fonte: Adaptado de Tidd, Bessant, \&Pavitt (2005). Managing Innovation: integrating technological, market and organizational change (p. 68). 4.ed. John Wiley\& Sons, Ltd: Chicester.

A etapa da busca investiga e analisa os cenários internos e externos na procura por sinais de inovação potencial como oportunidades de pesquisa ou demanda de determinado cliente. A seleção tem como objetivo definir quais das informações ou sinais poderão lograr futuro desenvolvimento na organização. Já a implementação diz respeito ao ato de se fazer a tradução da potencialidade da ideia inicial de algum empreendimento e lançá-lo em determinado mercado. Após a escolha do conceito de negócio, a organização precisa desenvolvê-lo até a etapa final. No que se refere à aprendizagem, as empresas têm a oportunidade de se aperfeiçoar com a progressão desta fase, de tal maneira que possam construir sua base de conhecimento e aperfeiçoar as formas de gestão do processo inovador (Tidd, Bessant e Pavitt, 2005).

Na análise de Desouza et al. (2009), conforme a Figura 2, as seguintes fases do processo de inovação representam as mais comumente utilizadas. Essas etapas estão interligadas de forma cíclica, ou seja, se uma ideia é gerada interna ou externamente, ela se move ao longo de outras fases antes de ser integralmente aprovada em determinada empresa ou esfera do mercado. 


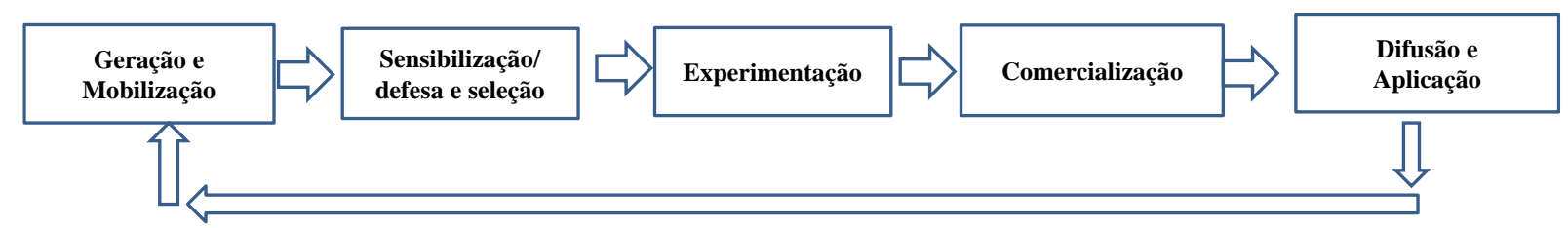

Figura 2. Modelo do Processo de Inovação de Desouzaet al. (2009)

Fonte: Desouza, K. C., Dombrowski, C., Awazu, Y.,Baloh, P., Papagari, S., Jha, S., \& Kim, J.(2009). Crafting organizational innovation processes (p.10). Innovation: management, policy \& practice. 11(1).

A geração de ideias é facilitada pela criação de um ambiente mais informal e democrático. As ideias podem ocorrer de forma espontânea por intermédio de caixas de sugestões ou de maneira induzida (Desouza et al., 2009). A mobilização de ideias diz respeito a fontes de ideias conectadas por meio dos departamentos situados nas áreas mais úteis (Desouza et al., 2009). A sensibilização/defesa e seleção da ideia podem ser compreendidas como a identificação de benefícios potenciais e problemas presentes em determinado período. (Desouza et al., 2009). A experimentação refere-se a um processo interativo de desenvolvimento da ideia, criação de um protótipo, análise da sua aplicabilidade para resolução de problemas específicos e avaliação de determinado contexto (Desouza et al., 2009). Enquanto a experimentação enfatiza a possibilidade de se executar uma ideia, a comercialização incide sobre o impacto potencial dessa ideia no mercado. (Desouza et al., 2009). Desouza et al. (2009) declaram que a difusão compreende o processo de geração, manutenção e aceitação de uma inovação. Já aaplicação de certos tipos de inovação requer ouso de campanhas publicitárias ou de vendas,com base no conhecimento das necessidades dos clientes e na capacidade de se lançar mão daquele conhecimento.

\subsection{Arcabouço Analítico: Processo de Inovação}

Com base nos estudos de Tidd, Bessant e Pavitt (2005) e Desouza et al. (2009) foi elaborado um arcabouço analítico (Figura 3) que consiste numa síntese integrada desses modelos, cujo objetivo principal foi suprir algumas limitações inerentes a cada modelo pela falta de algumas etapas.

Revista de Administração e Inovação, São Paulo, v. 12, n.1, p.24-51, jan./mar. 2015. 


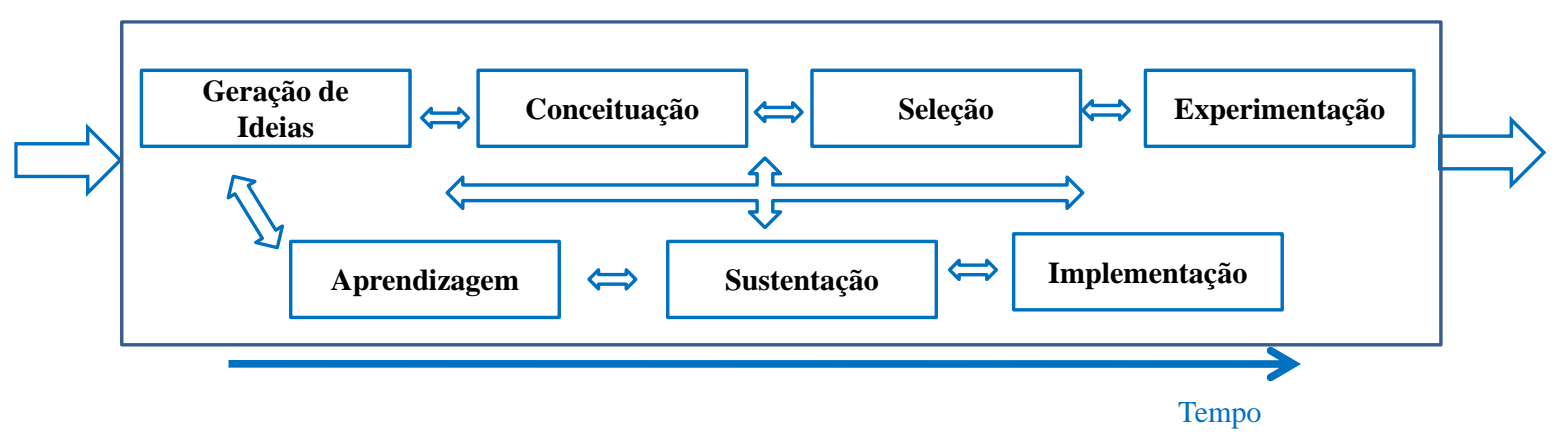

Figura 3. Arcabouço analítico do estudo.

Fonte: Autores (2014).

O detalhamento dos aspectos significativos para o processo estruturado de inovação contempla as definições e indicadores utilizados, conforme Quadro 1, onde são apresentadas as categorias de análise adotadas no presente estudo.

\section{Quadro 1: Definição Operacional e Indicadores do Modelo de Pesquisa.}

\begin{tabular}{|c|c|c|}
\hline $\begin{array}{l}\text { DESCRIÇÃO/ } \\
\text { CATEGORIAS }\end{array}$ & DEFINIÇÃO OPERACIONAL & INDICADORES \\
\hline Geração de Ideias & $\begin{array}{l}\text { Corresponde à captação de ideias advindas dos } \\
\text { ambientes interno e ambiente externo da } \\
\text { organização (TIDD; BESSANT; PAVITT, } \\
\text { 2008). }\end{array}$ & $\begin{array}{l}\bullet \quad \text { Estímulo à geração de } \\
\text { ideias; } \\
\text { • } \quad \text { Fontes internas e } \\
\text { externas. }\end{array}$ \\
\hline Conceituação & $\begin{array}{c}\text { Consiste em percorrer a ideia em vários setores } \\
\text { ou filiais da empresa, visando a preencher as } \\
\text { possíveis lacunas existentes (DESOUZA et al., } \\
2009 \text { ). }\end{array}$ & $\begin{array}{l}\text { - } \quad \text { Discussão da ideia; } \\
\text { - } \quad \text { Opinião dos } \\
\text { stakeholders. }\end{array}$ \\
\hline Seleção & $\begin{array}{l}\text { É um processo de avaliação e escolha da } \\
\text { melhor ideia, definida de acordo com critérios } \\
\text { claros: a ideia comercializável alinhada aos } \\
\text { objetivos estratégicos e à viabilidade financeira } \\
\text { do projeto (DESOUZA et al., 2009). }\end{array}$ & $\begin{array}{l}\text { Critérios de seleção; } \\
\text { - } \quad \text { Clareza e comunicação } \\
\text { dos critérios para os membros } \\
\text { da empresa. }\end{array}$ \\
\hline Experimentação & $\begin{array}{l}\text { Essa fase inclui a construção de um protótipo, } \\
\text { visando ao ajuste da ideia inovadora à cultura } \\
\text { da organização e às necessidades do cliente em } \\
\text { conjunto com as demais partes interessadas } \\
\text { (DESOUZA et al., 2009). }\end{array}$ & $\begin{array}{l}\text { Testes ou construção } \\
\text { de protótipos; } \\
\text { - } \quad \text { Adequação das ideias } \\
\text { aos stakeholders. }\end{array}$ \\
\hline Implementação & $\begin{array}{l}\text { É a fase de desenvolvimento da inovação, } \\
\text { comercialização, difusão e sua adoção no } \\
\text { mercado (DESOUZA et al., 2009; ROGERS, } \\
\text { 2003). }\end{array}$ & $\begin{array}{ll}\bullet & \text { Comercialização de } \\
\text { ideias; } & \\
\bullet & \text { Difusão de ideias; } \\
\bullet & \text { Adoção de ideias. } \\
\end{array}$ \\
\hline Sustentação & $\begin{array}{l}\text { Diz respeito ao apoio técnico, } \\
\text { acompanhamento, conclusão do projeto e } \\
\text { gestão (BERGLUND, 2007). }\end{array}$ & $\begin{array}{l}\text { • Apoiar/dar suporte à } \\
\text { ideia no pós-lançamento. }\end{array}$ \\
\hline Aprendizagem & $\begin{array}{l}\text { Revisão aberta e informada do projeto de } \\
\text { inovação com a prática do feedback constante } \\
\text { (TIDD, BESSANT; PAVITT, 2008). }\end{array}$ & $\begin{array}{l}\text { - } \quad \text { Mecanismos para se } \\
\text { gerar aprendizagem. }\end{array}$ \\
\hline
\end{tabular}

$$
\text { Fonte: Autores (2014). }
$$




\section{PROCEDIMENTOS METODOLÓGICOS}

O estudo constitui uma investigação descritiva, pois relata como ocorre o processo de inovação implementado por empresas fornecedoras associadas à rede PETROGAS/SE, observando-se e registrando-se as percepções, expectativas e sugestões dos participantes. Além disso, sua discussão estabelece correlações dos fatos e procura entender essa interação de forma reflexiva, expondo características do fenômeno estudado, buscando descrevê-lo, classificá-lo e interpretá-lo e relacioná-lo à teorização proposta (RUDIO, 2002; VERGARA, 2007).

Tal estudo também é caracterizado por ser de natureza qualitativa que se justifica pelo uso de procedimentos textuais estruturados com base nos relatos dos dirigentes das empresas pesquisadas por meio de entrevistas individuais (Creswell, 2007), uma vez que se propõe a relatar como ocorre o processo de inovação de empresas fornecedoras associadas à rede PETROGAS/SE, em que são observadas e registradas percepções, expectativas e sugestões dos participantes. Sobre a estratégia de investigação, diante da contemporaneidade e complexidade do fenômeno estudado, optou-se pelo uso do método de múltiplos casos, segundo o qual cada empresa pesquisada foi tratada como um caso.

Com o auxílio dos gestores do convênio SEBRAE/PETROBRÁS/SE, 11 empresas fornecedoras associadas à rede de Petróleo e Gás de Sergipe foram identificadas e consideradas mais inovadoras devido ao número de novos produtos/processos de empresas/ano, ao grau de exportação, à qualidade dos produtos e serviços inovadores, ao número de patentes (INPI, 2011) e aos prêmios recebidos em decorrência das inovações geradas nesse arranjo produtivo. A partir daí, foram entrevistados os dirigentes de 6 empresas, pois constatou-se que dentre as 11 levantadas, apenas 8 apresentavam inovações comprovadas e 2 destas não tiveram interesse em participar da pesquisa. Todos os entrevistados são proprietários e gestores dessas empresas, exercendo a posição de diretorpresidente, sócio-fundador/administrador ou gerente comercial. Para garantir o anonimato das informações, as empresas foram denominadas de E1, E2, E3, E4, E5 e E6.

$\mathrm{Na}$ coleta dos dados realizada no primeiro semestre de 2011, foram realizadas entrevistas semiestruturadas de aproximadamente 75 minutos, com o suporte de um protocolo de pesquisa composto por nove categorias analíticas e quinze questões secundárias, relacionadas conforme os indicadores sugeridos no arcabouço analítico (Figura 3). Assim, as 6 entrevistas foram guiadas por um roteiro aplicado junto aos respectivos dirigentes das organizações selecionadas.

Revista de Administração e Inovação, São Paulo, v. 12, n.1, p.24-51, jan./mar. 2015. 
Foi definida a técnica de análise de conteúdo de acordo com a metodologia proposta por Bardin (2004), aplicada conforme suas fases chave: 1) a pré-análise; 2) a exploração do material; 3) o tratamento dos resultados e 4) interpretação.

Na primeira etapa, foram demarcadas as unidades de significados mais relevantes. Na segunda etapa, cada categoria e subcategoria analítica (unidade de registro/análise) recebeu um código e as unidades de significado foram codificadas conforme sua adequação a determinada categoria temática, conforme dispostas a seguir: características gerais do processo de inovação, geração de ideias, conceituação, seleção, experimentação, implementação, sustentação e aprendizado. Depois de selecionadas as unidades de significado de acordo com a ordenação dos dados, elas foram tratadas com base no índice de frequências e percentagens dos temas/palavras-chave dispostos no texto.

A terceira etapa correspondeu ao tratamento e à interpretação dos resultados. Os dados obtidos pelas entrevistas foram interpretados em consonância com o referencial teórico do estudo com a finalidade de verificação das devidas correspondências temáticas.

As citações referentes aos relatos dos dirigentes entrevistados foram identificadas com a letra $\mathrm{E}$ (empresa), seguida de um numeral (expresso nos extratos de 1 a 6) que corresponde à identificação da empresa selecionada, ou seja, E1 corresponde à primeira empresa pesquisada, E2, à segunda e assim por diante. Também foi incluída na citação a linha inicial do texto extraído, por exemplo, (E1, 110) significa que o trecho se refere a empresa E1 e iniciou na linha 110 do texto transcrito.

A qualidade e a confiabilidade dos dados contemplaram a validação comunicativa, uma vez que, após a entrevista, foi obtido o consentimento do entrevistado para tratamento e análise dos conteúdos de seus relatos (Flick, 2004). A descrição rica e detalhada dos dados serviu como critério de validade e confiabilidade da pesquisa, em que se descreveu de forma minuciosa o cenário da pesquisa e as fases de sua realização, assim como narrados com densidade os relatos dos líderes entrevistados (Merrian, 1998; Paiva Júnior, Leão \& Melo, 2011). Outra técnica utilizada de validade e confiabilidade do estudo consistiu na triangulação de informações, uma vez que constitui um modo de institucionalização de perspectivas e métodos teóricos, buscando reduzir eventuais inconsistências e contradições que causassem viés na pesquisa, compondo um quadro mais evidente do fenômeno por meio da convergência, conforme Gaskell e Bauer (2005).

\section{ANÁLISE DOS RESULTADOS}

Revista de Administração e Inovação, São Paulo, v. 12, n.1, p.24-51, jan./mar. 2015. 
A descrição do modo como ocorre o processo de inovação desenvolvido pelas empresas fornecedoras associadas à rede PETROGAS/SE conta com os relatos analíticos referentes aos resultados alcançados com base nas nove categorias já discutidas. Tais resultados foram agrupados em dois blocos analíticos, a saber: no primeiro bloco, as empresas pesquisadas foram caracterizadas conforme o processo de inovação (tipo, grau, se são inovadoras e se possuem uma gestão do processo de inovação); e, no segundo bloco, foram identificadas e descritas as etapas do processo de inovação existentes nas empresas investigadas.

\subsection{Caracterização das Empresas quanto ao Processo de Inovação}

Quanto ao tipo de inovação, todas as empresas estudadas revelam a existência de inovação tecnológica de produto, serviço e processo, de acordo com a definição dos tipos de inovação proposta por Francis \& Bessant (2005) e pelo relatório PINTEC (2008), exceto as empresas E4 e E5, que só possuem inovação de serviço. Foi identificada certa multifuncionalidade das empresas quanto ao tipo de inovação, segundo a qual os dirigentes demonstraram forte percepção de oportunidade de mercado voltada para o atendimento das necessidades do cliente, reconhecida com base no conhecimento tácito. Não foi constatado nenhum tipo inovação organizacional em qualquer das empresas, o que nos leva a crer na existência de alguma dificuldade no sentido de elas dispor em de determinadas competências gerenciais e demonstrarem pouca familiaridade com a área administrativa.

Quanto ao tipo de inovação, a pesquisa aqui relatada está em consonância com o estudo de Silva, Souza e Freitas (2012) quanto ao processo de inovação no setor moveleiro de Campina Grande/PB, exceto pelo tipo de inovação organizacional. Nesse estudo, também foi detectada certa multifuncionalidade das empresas no que concerne ao tipo de inovação, destacando-se a de produtos, em que se constata melhoria dos itens já existentes e introdução de novos produtos no mercado.

No que tange ao grau de inovação, revelou-se prevalente o incremental. Todas as empresas fazem melhorias significativas em seus produtos, serviços ou processos, o que se coaduna com os resultados encontrados noestudo de Santos, Basso e Kimura (2012, p. 121), quando afirmam que "o perfil da capacidade de inovar das firmas brasileiras está mais voltado para a replicação de conhecimento e inovações incrementais do que a busca de desenvolvimento de inovações radicais e estratégicas para a firma nacional".

Por outro lado, as empresas E1, E2 e E6 destacam-se com a inovação radical, fato este que exige dos gestores maior esforço criativo e habilidades diferenciadas para gerir situações imprevistas, desconhecidas, arriscadas e de alto custo. Essas empresas dispõem de um processo de inovação mais

Revista de Administração e Inovação, São Paulo, v. 12, n.1, p.24-51, jan./mar. 2015. 
estruturado devido às exigências das certificações a que se submeteram. Acredita-se que pelo fato de possuírem uma estrutura eficiente de trabalho, isso facilita a gestão das inovações radicais, a saber: "Nossa experiência no ramo ajuda muito para desenvolvermos novos produtos e processos para o mercado (E2, 53), [...] temos 09 patentes e o retorno é compensador" (E2, 195). Este depoimento reforça o que diz Junarsin (2009), quanto à inovação radical ser mais arriscada, incerta, cara e difícil de ser gerida, porém necessária numa empresa cujos líderes desejamalcançar vantagemcompetitivanum ambiente turbulento denegócioscomo o atual.

Não obstante o fato de todas as organizações se considerarem inovadoras, algumas delas são detentoras de patentes (E2), vendem seus produtos para outros países (E1, E2 e E3) e são reconhecidas nacional e internacionalmente (E1, E2, E3 e E6). Os dirigentes dessas empresas revelam a existência de características que sugerem um ambiente propício à inovação. Assim, no depoimento do dirigente da empresa E2 ele destaca sua visão do processo de inovação:

Nós somos uma equipe bastante experiente na área de petróleo, todos nós temos, no mínimo, 30 anos nessa área. Proporcionamos um ambiente participativo e criativo e temos visão de mercado. Esses fatores nos favorecem a desenvolvermos nossas inovações, termos patentes e fazermos exportações. A inovação permite que você se diferencie no mercado (E2, 33).

Por outro lado, duas outras empresas (E4 e E5) manifestaram dificuldades no sentido de perceberem suas inovações, talvez pelo fato de desconhecerem o que realmente define uma inovação e por terem pouca qualificação a respeito disso, mesmo afirmando serem inovadoras com base no reconhecimento de terceiros. Provavelmente, sejam esses os fatores que levem à insegurança na resposta a propósito de uma empresa ser ou não inovadora e, também, pelo fato de a inovação ser considerada, tal como o empreendedorismo, um conceito polissêmico, ou seja, um termo contendo diferentes concepções, o que se agrava quando se trata de distinções conceituais de inovação no âmbito interssetorial (Oliveira et al.,2014). Esse fato fica ilustrado por um depoimento que revela o favorecimento da prática inovadora quando o entrevistado afirma: "acreditamos que somos inovadores em nossos serviços prestados, pois temos um ambiente propício à criatividade e abertura de ideias, mas temos dificuldade de perceber a inovação. As pessoas é que nos dizem se estamos inovando" (E5, 23).

As empresas também foram caracterizadas quanto à gestão do processo de inovação. Foi detectado que as organizações que possuem certificação internacional (Norma ISO, SGI) dispõem de um processo mais estruturado e gerenciado de inovação, exceto a empresa E4,que possui certificação conforme essas normas, entretanto seu dirigente afirmou não contar com um processo consolidado de inovação e manifestam certa dificuldade de perceber que seus novos artefatos constituem, de fato, expressões do processo inovador. Segundo o dirigente:

Revista de Administração e Inovação, São Paulo, v. 12, n.1, p.24-51, jan./mar. 2015. 
Gerenciamos nossas inovações seguindo o mesmo procedimento das normas ISO: definimos nossos objetivos, criamos procedimentos e qualificamos nossos empregados, auditamos nossos processos e medimos a satisfação dos nossos clientes, além de acompanharmos os principais indicadores $(\mathrm{E} 1,130)$.

Tal relato se revela estar em consonância com os achados dos estudos de Mc Adam e Armstrong (2001), que mostram uma correlação positiva entre os sistemas de gestão da qualidade e o processo de inovação. Assim, pelo perfil identificado nas empresas pesquisadas, todas inovam com intensidades distintas. Foi identificado, também, que os dirigentes das empresas que mais inovam possuem algumas características comuns: eles dispõem de expertise na área de petróleo e gás; sentem-se motivados pelas suas realizações; trabalham de acordo com as necessidades dos clientes; possuem uma estrutura organizada e com procedimentos definidos; oferecem treinamentos para suas equipes e reconhecem mais rapidamente as ideias com potencial de inovação, utilizando-se de parcerias com instituições de fomento e pesquisa para a obtenção de recursos financeiros, visando a lançar suas inovações no mercado.

Existe certa carência de gestão profissionalizada nas empresas E3, E4 e E5. Por outro lado, mesmo em se tratando das empresas que relataram dispor de processos mais estruturados, foi observado que seus dirigentes investem pouco em um ambiente de cultura inovativa, além de não analisarem sistematicamente os impactos gerados por suas práticas inovadoras, a exemplo do que ocorre na empresa E6. Tal constatação nos reporta a Rajegopal (2012), quando observa que é imperativo analisar o modo como a liderança da empresa dá suporte à cultura inovadora e ao processo de execução de determinada estratégia de inovação, a começar pela destinação de recursos em seu orçamento. $\mathrm{O}$ autor complementa que deve ser avaliado também o modo como a equipe da base se sente motivada para executar as novas ideias. Com isso, vão surgindo passos para a mudança na cultura inovativa da empresa desde seu interior.

\subsection{Etapas do Processo de Inovação das Empresa}

Conforme sintetiza o Quadro 2, as 6 (seis) empresas estudadas apresentam algumas semelhanças e diferenças no processo de inovação disposta em maior ou menor intensidade nas etapas descritas.

No que diz respeito à etapa geração de ideias, é comum se notar entre as empresas o surgimento das ideias a partir das necessidades dos clientes e oportunidades tecnológicas baseadas em pesquisas internas ou em parcerias com outras instituições de pesquisa e fomento. Portanto, os dirigentes das empresas pesquisadas utilizam fontes internas e externas de conhecimento para nutrirem

Revista de Administração e Inovação, São Paulo, v. 12, n.1, p.24-51, jan./mar. 2015. 
a geração de novas ideias, exceto as empresas E3 e E5, que utilizam apenas as fontes internas (Quadro 2): "Nós buscamos novas ideias através de reuniões frequentes com a participação dos sócios e os empregados mais envolvidos no processo de inovação" (E1, 169). Essa evidência corrobora com a visão de Tidd, Bessant e Pavitt (2005) de que é importante aproveitar as ideias comuns manifestadas pelos membros das equipes, especialmente para incrementar melhorias em produtos e processos.

As ideias surgem a partir de reuniões com os empregados e contatos com os clientes e demais parceiros da empresa, pois: “[...] é através do mercado, consultando os nossos principais clientes, explorando e entendendo suas necessidades mais críticas e seus desejos que surgem novas ideias” (E2, 133). Segundo Tidd, Bessant e Pavitt (2005), é importante coletar informações externas à empresa, somadas ao conhecimento internalizado e combinado de forma criativa.

Foi observado que apenas as empresas E1, E2 e E6 possuem um sistema de registro das ideias, devido às exigências das normas ISO ou SGI e somente os colaboradores envolvidos no processo de inovação possuem acesso ao tal sistema. Também se observou que a prática de incentivo à geração de ideias com premiações simbólicas que só acontecem nas empresas E4 e E6, com critérios de avaliação para aquelas ideias julgadas com potencial de inovação. Esse pouco incentivo das empresas à geração ideias pode ser considerado fator limitante à participação efetiva dos membros das equipes, conforme reforçam os autores Desouza et al. (2009) e Scherer e Carlomagno (2009), quando mencionam a importância a ser destinada para o estímulo de ideias dentro das empresas visando à alimentação contínua de novas ideias.

Quanto à conceituação das ideias geradas, todas as empresas, conforme Quadro 2, discutem com seus empregados envolvidos no processo de inovação sobre os prós e contras das ideias, no sentido de refiná-las com fins de aplicação de modo eficaz. Durante as seções de discussão, também foram consideradas as opiniões dos clientes principais e de alguns parceiros: "nós aprofundamos o conceito de uma nova ideia através de reuniões com o cliente e empregados envolvidos. [...] a ideia é discutida internamente e, se for aprovada, vamos executá-la" (E1,183). Esse relato converge para as ideias de Desouza et al. (2009), mostrando que a discussão de ideias proporciona a retirada de excessos de informação e a inclusão de novos conceitos.

Um aspecto que pode representar fator limitador dessa fase reside na informalidade na condução dessas reuniões e os poucos registros gerados. Apenas as empresas E1, E2 e E6 formalizam os registros das principais ideias com seus respectivos argumentos a favor e contra e os utilizam durante a seleção e desenvolvimento do conhecimento organizacional. Nas demais empresas, muitas das reflexões são perdidas ou esquecidas e, como consequência, tem-se o surgimento de problemas nas demais fases. Nesse tema, Johnson (2010) assinala a importância das anotações, pois a discussão sobre 
o potencial de uma ideia depende de determinados registros que podem posteriormente facilitar a sistematização daquele conhecimento tácito.

No que se refere à seleção de ideias, todas as empresas possuem critérios para escolher a melhor ideia com potencial de inovação (Quadro 2), porém, somente as empresas E1, E5 e E6 demonstram a importância de comunicá-las, de forma clara, aos colaboradores: "todos os funcionários conhecem os critérios de seleção das novas ideias e tais critérios são transmitidos informalmente" (E5, $52)$.

Os critérios expostos pelos dirigentes entrevistados revelam estar em conformidade com os sugeridos por Scherer e Carlomagno (2009). Observou-se também a ausência de alinhamento estratégico de novas ideias aos objetivos da empresa e foram detectadas falhas na disposição de questões de competências conceituais da esfera tecnológica, inclusive no que tange à execução de projetos. As empresas E2, E3 e E5 não incluíram como critério esses alinhamentos pela falta de consistência das estratégias existentes ou pelo fato de elas não disporem de um planejamento estratégico adequado, além de manifestarem a não valorização de questões relativas a pessoas, no âmbito do aperfeiçoamento das condições de trabalho de suas equipes de operação.

As empresas pesquisadas desenvolvem a fase de experimentação, exceto as empresas E4 e E5, de acordo com o Quadro 2. Tal fase é efetivada a partir da seleção da ideia com potencial inovador. Logo, as informações são traduzidas para linguagem técnica, dando origem a um primeiro exemplar (protótipo) ou, a depender do tipo de inovação, são realizados apenas os testes para se avaliar a funcionalidade do produto. Uma vez produzido o protótipo ou realizados os testes, os resultados são avaliados conjuntamente entre as áreas envolvidas e com os clientes para verificação de atendimento das expectativas e, caso não sejam atendidas, o processo é reiniciado ou finalizado, conforme assinala Desouza et al., (2009).

As empresas E1 e E2 possuem um setor de P\&D com laboratórios para a obtenção de conhecimento tecnológico. Além disso, outra forma de realizarem pesquisas, utilizada tanto pelas empresas E1 e E2 como pelas demais, consiste na busca de parcerias por intermédio da PETROBRÁS, de centros de pesquisas e das universidades, visando à obtenção de tecnologias desenvolvidas por outros ou tentando complementar as tecnologias desenvolvidas internamente. Tal fato converge com o resultado do estudo de Santos, Basso e Kimura (2012, p. 120), no qual eles relatam que "as empresas brasileiras direcionam seus investimentos para aquisição de conhecimento ou terceirização de pesquisa e desenvolvimento, em detrimento ao fomento destes no seu interior."

No tocante à comercialização e difusão da inovação (Quadro 2), as empresas pesquisadas possuem um setor para comercialização das suas inovações, destacando-se as empresas E1 e E2 que 
possuem de forma mais estruturada as práticas de comercialização, mas, por outro lado, tais práticas não estão embasadas em qualquer estudo aprofundado de marketing que demonstre o comportamento e as principais necessidades do consumidor peculiar do setor de P\&G. Sobre a difusão de inovação, algumas técnicas são rudimentares a ponto de os dirigentes das empresas E1 e E6 confirmarem a diminuta necessidade de difundirem suas novidades tecnológicas, talvez pelo fato de já serem conhecidas no mercado. Eles encaram como desnecessária a necessidade de investirem em meios de comunicação mais elaborados, como divulgação em revistas técnicas e feiras de $\mathrm{P} \& \mathrm{G}$ e distribuição do portfólio da empresa, conforme ilustra o relato a seguir:

Temos um site, enviamos e-mails para eles. Investimos pouco em propaganda, mas apesar de conseguirmos bons resultados por já termos um nome conceituado no mercado, percebemos que uma melhor difusão poderia incrementar nossos números $(\mathrm{E} 6,123)$.

A rede de negócios voltada para o processo de comercialização e difusão das inovações pareceu ter sido pouco acessada, não obstante o fato de todos os dirigentes terem ratificado a sua relevância: "a rede nos ajuda na divulgação das nossas inovações, nos abriu um leque de opções, através da rodada de negócios e da troca de informações que o ambiente propicia” (E5, 77). Portanto, esse raciocínio corrobora com as constatações de Ormerod e Rosewell (2009), quando revelam que as redes empresariais têm recebido grande atenção por parte dos pesquisadores e empresários por serem um meio eficaz na divulgação rápida da informação, na adesão de usuários e por representarem a facilidade de custo baixo para expansão do empreendimento. 


\section{Quadro 2: Etapas do Processo de Inovação por Empresa}

\begin{tabular}{|c|c|c|c|c|c|c|}
\hline \multirow[b]{2}{*}{ 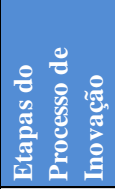 } & \multicolumn{6}{|c|}{ EMPRESAS PESQUISADAS } \\
\hline & E1 & E2 & E3 & E4 & E5 & E6 \\
\hline 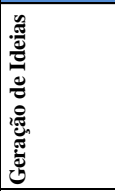 & $\begin{array}{l}\text { Através de Reuniões } \\
\text { internas com o pessoal } \\
\text { envolvido e contatos com } \\
\text { os clientes, professores e } \\
\text { instrutores; }\end{array}$ & \begin{tabular}{|l} 
Surge a partir das \\
necessidades do mercado \\
(clientes).
\end{tabular} & $\begin{array}{l}\text { Através de discussão entre } \\
\text { os sócios sobre os } \\
\text { principais problemas dos } \\
\text { clientes e oportunidades } \\
\text { tecnológicas; }\end{array}$ & $\begin{array}{l}\text { As ideias surgem a partir } \\
\text { das necessidades } \\
\text { identificadas no mercado } \\
\text { de gás e de pesquisas } \\
\text { internas. }\end{array}$ & $\begin{array}{l}\text { Reunião com os } \\
\text { empregados e discussão } \\
\text { entre os sócios; } \\
\text { Não há procedimentos e } \\
\text { existe pouco incentivo } \\
\text { interno a geração de ideias. }\end{array}$ & $\begin{array}{l}\text { A busca de ideias é feita } \\
\text { através do mercado; Há } \\
\text { discussão com os parceiros } \\
\text { internos e externos e } \\
\text { pesquisas na internet; }\end{array}$ \\
\hline نू. & $\begin{array}{l}\text { Discussão interna com os } \\
\text { empregados diretamente } \\
\text { envolvidos sobre os prós e } \\
\text { contras da ideia; Há } \\
\text { valorização da opinião do } \\
\text { cliente; Há registros de } \\
\text { toda a discussão. }\end{array}$ & $\begin{array}{l}\text { Há discussão interna e a } \\
\text { ideia passa por setores } \\
\text { diferentes para ser } \\
\text { avaliada. A opinião do } \\
\text { cliente é considerada e há } \\
\text { registros de toda a } \\
\text { discussão. } \\
\end{array}$ & $\begin{array}{l}\text { Discussão interna junto } \\
\text { com os setores envolvidos. } \\
\text { Há valorizção da opinião } \\
\text { do cliente; Falta a } \\
\text { realização de registros. }\end{array}$ & $\begin{array}{l}\text { Há discussão interna junto } \\
\text { com os setores mais } \\
\text { envolvidos: engenharia, } \\
\text { projetos e RH; } \\
\text { Não há registros do } \\
\text { resultado da discussão. }\end{array}$ & $\begin{array}{l}\text { Discussão interna sobre os } \\
\text { prós e contras da ideia; Há } \\
\text { valorização da opinião do } \\
\text { cliente; Falta a realização de } \\
\text { registros. }\end{array}$ & $\begin{array}{l}\text { Discussão interna sobre os } \\
\text { prós e contras da ideia; } \\
\text { Há valorização da opinião } \\
\text { do cliente; Uso do PDCA; } \\
\text { Há registros de toda a } \\
\text { discussão. }\end{array}$ \\
\hline 胥 & $\begin{array}{l}\text { Possui critérios claros e } \\
\text { comunicados a todos os } \\
\text { envolvidos internamente. }\end{array}$ & $\begin{array}{l}\text { Os critérios são claros e } \\
\text { devidamente registrados } \\
\text { em procedimentos } \\
\text { internos. }\end{array}$ & $\begin{array}{l}\text { Os critérios são } \\
\text { estabelecidos, mas ficam } \\
\text { restritos aos sócios. }\end{array}$ & \begin{tabular}{|l|} 
Possui critérios claros, \\
porém são apenas do \\
conhecimento da diretoria.
\end{tabular} & $\begin{array}{l}\text { Todos os funcionários } \\
\text { conhecem os critérios de } \\
\text { maneira informal; }\end{array}$ & $\begin{array}{l}\text { Possui critérios claros e } \\
\text { comunicados para todos os } \\
\text { empregados envolvidos; } \\
\text { Todos os critérios são } \\
\text { registrados. }\end{array}$ \\
\hline 密 & $\begin{array}{l}\text { Realização de protótipos } \\
\text { com testes feitos na } \\
\text { PETROBRÁS e na } \\
\text { empresa de clientes. } \\
\text { Desenvolve tecnologias } \\
\text { com apoio do FINEP e } \\
\text { PROMINP. Possui um }\end{array}$ & $\begin{array}{l}\text { Realização de protótipos } \\
\text { com testes feitos na } \\
\text { PETROBRÁS e no } \\
\text { CENPES, na empresa do } \\
\text { cliente; Desenvolve } \\
\text { tecnologias com apoio do } \\
\text { CENPES. Possui um }\end{array}$ & $\begin{array}{l}\text { Os testes são realizados na } \\
\text { própria empresa e na do } \\
\text { cliente; As tecnologias são } \\
\text { desenvolvidas na própria } \\
\text { empresa com recursos } \\
\text { próprios. }\end{array}$ & Não faz. & Não faz. & $\begin{array}{l}\text { Os testes são realizados na } \\
\text { própria empresa e na do } \\
\text { cliente;As tecnologias são } \\
\text { desenvolvidas na própria } \\
\text { empresa com recursos } \\
\text { próprios. }\end{array}$ \\
\hline 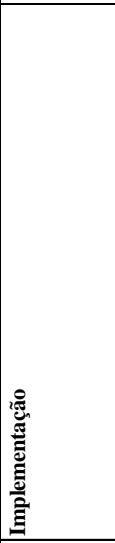 & $\begin{array}{l}\text { Os diferenciais da empresa } \\
\text { são: qualidade do produto } \\
\text { e serviço; certificação } \\
\text { internacional; assessoria in } \\
\text { loco; experiência no ramo. } \\
\text { A comunicação das } \\
\text { inovações é feita via } \\
\text { jornalzinho interno; } \\
\text { Os fatores que levam o } \\
\text { cliente a adotar os } \\
\text { produtos e serviços são: } \\
\text { alta confiabilidade dos } \\
\text { produtos, seviços e } \\
\text { informações; preço } \\
\text { acessível; qualidade; } \\
\text { percepção dos resultados } \\
\text { pelo cliente e empregados } \\
\text { envolvidos. }\end{array}$ & $\begin{array}{l}\text { Os diferenciais da } \\
\text { empresa são: Realização } \\
\text { de palestras para } \\
\text { demonstração dos } \\
\text { benefícios; qualidade dos } \\
\text { produtos; grande } \\
\text { expertise dos sócios; } \\
\text { preço acessível. A difusão } \\
\text { da inovação é feita } \\
\text { através de visita aos } \\
\text { clientes e parcerias com } \\
\text { fornecedores. Os fatores } \\
\text { que levam o cliente a } \\
\text { adotar os produtos e } \\
\text { serviços são: alta } \\
\text { confiabilidade dos } \\
\text { produtos; preço acessível; } \\
\text { qualidade; apoio da } \\
\end{array}$ & $\begin{array}{l}\text { Os diferenciais da empresa } \\
\text { são: Avaliação do produto } \\
\text { do concorrente; redução } \\
\text { do prazo; preço acessível e } \\
\text { assitência técnica. A } \\
\text { difusão da inovação é feita } \\
\text { através de e-mails, site da } \\
\text { empresa e distribuição de } \\
\text { folders. Os fatores que } \\
\text { levam o cliente a adotar os } \\
\text { produtos e serviços são: } \\
\text { confiabilidade do produto e } \\
\text { do serviço; suporte técnico } \\
\text { e custo. }\end{array}$ & $\begin{array}{l}\text { Os diferenciais da empresa } \\
\text { são: A imagem positiva da } \\
\text { empresa e a qualidade dos } \\
\text { serviços. A comunicação } \\
\text { das inovações é feita via o } \\
\text { site da empresa. Os fatores } \\
\text { que levam o cliente a } \\
\text { adotar os produtos e } \\
\text { serviços são: Segurança, } \\
\text { qualidade da matéria-prima } \\
\text { e suporte técnico. }\end{array}$ & $\begin{array}{l}\text { Os diferenciais da empresa } \\
\text { são: Preço acessível e prazo. } \\
\text { A comunicação das } \\
\text { inovações é feita via e-mail, } \\
\text { distribuição de folders e } \\
\text { divulgação atavés da rede } \\
\text { PETROGAS/SE. }\end{array}$ & $\begin{array}{l}\text { Os diferenciais da empresa } \\
\text { são: suporte técnico, } \\
\text { adequação às necessidades } \\
\text { do cliente. } \\
\text { A comunicação das } \\
\text { inovações é feita via } e \text { - } \\
\text { mail e contatos informais. } \\
\text { Os fatores que levam o } \\
\text { cliente a adotar os } \\
\text { produtos e serviços são: } \\
\text { redução de custo e } \\
\text { melhoria no processo, bem } \\
\text { como quando o cliente } \\
\text { visualiza resultados } \\
\text { concretos. }\end{array}$ \\
\hline 宽 & $\begin{array}{l}\text { Realização de assessorias } \\
\text { in loco e treinamentos } \\
\text { para os clientes. }\end{array}$ & $\begin{array}{l}\text { Treinamento para os } \\
\text { clientes para utilização } \\
\text { adequada do produto ou } \\
\text { processo. }\end{array}$ & $\begin{array}{l}\text { Capacitação do cliente } \\
\text { quanto ao uso adequado } \\
\text { do produto ou processo; } \\
\text { Visitas in loco. }\end{array}$ & $\begin{array}{l}\text { Distribuição de cartilhas; } \\
\text { acompanhamento in loco } \\
\text { de forma pontual e } \\
\text { orientação informal. }\end{array}$ & $\begin{array}{l}\text { Orientação pessoal e } \\
\text { informal. }\end{array}$ & $\begin{array}{l}\text { Acompanhamento gratuito; } \\
\text { Treinamento para os } \\
\text { clientes. }\end{array}$ \\
\hline 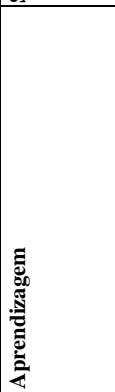 & $\begin{array}{l}\text { O processo de } \\
\text { aprendizagem acontece } \\
\text { através de reuniões } \\
\text { internas, treinamento do } \\
\text { cliente, realização de } \\
\text { pesquisas de opinião, } \\
\text { Acompanhamento in loco, } \\
\text { utilização de } \\
\text { procedimentos formais, } \\
\text { realização de uditorias no } \\
\text { processo e utilização de } \\
\text { benchmarking. }\end{array}$ & $\begin{array}{l}\text { É feito um planejamento } \\
\text { antes de realizar cada } \\
\text { etapa; Prática de } \\
\text { feedback; } \\
\text { Elaboração de práticas } \\
\text { preventivas, após } \\
\text { avaliação dos erros em } \\
\text { cada ciclo de inovação. }\end{array}$ & $\begin{array}{l}\text { Revisões corretivas } \\
\text { frequentes do processo em } \\
\text { cada fase. }\end{array}$ & \begin{tabular}{|l} 
Reuniões corretivas \\
internas; realização de \\
auditorias e revisão \\
periódica dos processos \\
realizados.
\end{tabular} & $\begin{array}{l}\text { São feitas reuniões sobre os } \\
\text { erros do processo realizado } \\
\text { com busca de alternativas de } \\
\text { solução visando a correção } \\
\text { do problema. }\end{array}$ & $\begin{array}{l}\text { São realizadas reuniões } \\
\text { internas; Treinamento para } \\
\text { o cliente; pesquisas de } \\
\text { opinião; acompanhamento } \\
\text { in loco; utilização de } \\
\text { procedimentos formais; } \\
\text { auditorias no processo; } \\
\text { Realização de } \\
\text { benchmarking. }\end{array}$ \\
\hline
\end{tabular}

Fonte: Centurión, W. C. (2012). Processo de inovação de empresas fornecedoras associadas à rede PETROGAS/SE: um estudo multicasos. 202f. Dissertação de Mestrado em Administração. Universidade Federal de Pernambuco, Recife. 
No que concerne à adoção de ideias, todos os dirigentes pesquisados informaram que uma inovação só será aceita pelo mercado se incrementar a qualidade ou se seus produtos se mostrarem confiáveis, bem como se tal inovação agregar valor para o cliente e possuir um preço acessível em relação aos concorrentes. Tais conceitos para a inserção de uma nova ideia no mercado estão de acordo com o conceito desenvolvido por Rogers (2003) e Desouza et al., (2009).

A etapa de sustentação, por sua vez, revela que todos os dirigentes compreendem a importância do suporte dado aos clientes após o lançamento da inovação no mercado. São realizados treinamentos para os clientes e visitas in loco, exceto pelas empresas E4 e E5 (Quadro 2), que apenas distribuem cartilhas e fazem orientações pontuais e informais, respectivamente. Tal fato está em consonância com os estudos de Berglund (2007). Como forma de elucidar esse fato, segue depoimento de um dos gestores entrevistados:

Sempre que lançamos um produto no mercado, disponibilizamos uma equipe para treinar e acompanhar o desempenho do produto. Com os treinamentos, percebemos que diminuem as solicitações e você cria um canal de comunicação que facilita de forma mais rápida a solução de problemas, além de fortalecer a imagem da empresa junto ao cliente e o mesmo ficar mais satisfeito (E2, 244).

Proporcionar suporte aos clientes após o lançamento de produtos e serviços inovadores no mercado não é uma prática comum entre as pequenas e médias empresas brasileiras. Tal fato ainda é considerado um serviço diferenciado, principalmente por se tratar de MPE que geralmente possuem recursos limitados. Com isso, as empresas sergipanas de $\mathrm{P} \& \mathrm{G}$ estudadas se destacam desse panorama brasileiro e ratificam esse diferencial. Por outro lado, essa prática ainda é desenvolvida de maneira informal, baseada na experiência de cada dirigente e, na maioria das vezes, é customizada.

Sobre a etapa denominada aprendizado (Quadro 2),embora as empresas analisadas utilizem técnicas de desenvolvimento da aprendizagem ao longo do processo de inovação, ainda existe certo hiato em termos de adoção das melhores práticas como sugere a teoria estudada (Desouza et al., (2009). A prática da aprendizagem exige um grande esforço reflexivo por parte dos gestores e empregados envolvidos no processo de inovação, visando a analisar de forma profissional e justa os acertos e erros de cada etapa com o propósito de serem traçadas ações de melhoria, de forma corretiva para os processos atuais e preventiva para os futuros.

Os formatos de gestão direcionados para o desenvolvimento da aprendizagem ajudam as empresas a reduzirem as incertezas inerentes às inovações e a melhorarem a capacidade decisória dos

Revista de Administração e Inovação, São Paulo, v. 12, n.1, p.24-51, jan./mar. 2015. 
seus dirigentes no que concerne à inovação tecnológica (Tidd, Bessant e Pavitt, 2005). Com relação à empresa E1, ela se destacou com respeito à valorização desse tema a ponto de seu dirigente relatar a existência de mecanismos internos exitosos para aperfeiçoar o aprendizado da equipe:

Pedimos aos clientes que nos avaliem através de pesquisas de opinião. Além disso, fazemos acompanhamento dos nossos sistemas na empresacliente para checarmos in loco o que podemos melhorar e visitamos frequentemente empresas concorrentes de grande porte para observar suas melhores práticas e auditamos nossos processos frequentemente $(\mathrm{E} 1$, 293).

Os dirigentes das empresas E3, E4 e E5 afirmam que efetuam revisões periódicas em seus sistemas de inovação, porém se percebe que o modo de gerar aprendizado por meio de erros e acertos ainda está incorporado na metodologia de trabalho dessas organizações. O processo demonstra ser mais corretivo, pois as discussões são geradas depois que ocorrem as falhas e existem poucos sistemas de prevenção de modo a evitá-las. Tidd, Bessant e Pavitt (2005) explicam que tal fato ocorre ainda por esses procedimentos de feedback não fazem parte da cultura de muitas empresas, uma vez que se exige tempo para reflexões das pessoas com respeito ao que ocorreu de positivo e negativo no processo, assim como se demanda a destinação de recursos financeiros para a adoção de tecnologias voltadas para eventuais ações preventivas, concepção que se coaduna com as recomendações de Rajegopal (2012), quando busca estimular as lideranças empresariais a investirem na cultura da inovação.

Existe pouca participação de especialistas dedicados ao desenvolvimento de programas de P\&D nas empresas E3, E4, E5 e E6, evidenciando uma excessiva dependência do conhecimento externo a exemplo da terceirização de estudos direcionados para desenvolvimento de expertise de inovação na área de $\mathrm{P} \& \mathrm{G}$. Além disso, ainda é baixo o número de mestres e doutores atuando em empresas deste setor produtivo (Santos, Basso e Kimura, 2012). Como ocorre na maior parte do país, ainda se observa uma grande distância entre as empresas de $P \& G$ e instituições de ensino, uma vez que são limitados os incentivos que representem atrativos para esses profissionais qualificados trabalharem em empresas privadas.

Sendo assim, dentre as seis empresas pesquisadas, o processo de inovação acontece de forma mais estruturada nas empresas E1, E2 e E6, ou seja, em 50\% delas. Isso se justifica, segundo a visão dos próprios dirigentes, por tais empresas possuírem um sistema de gestão integrada ou por serem certificadas em alguma norma ISO. Com isso, tais dirigentes tendem a gerir seu processo de inovação com maior facilidade, pois o sistema ou os procedimentos para a obtenção e manutenção da certificação de qualidade lhes auxiliam na organização de suas rotinas com base em diretrizes e indicadores definidos, exigindo uma dinâmica de capacitação contínua para os profissionais engajados

Revista de Administração e Inovação, São Paulo, v. 12, n.1, p.24-51, jan./mar. 2015. 
nos projetos de inovação, além de se requerer o envolvimento das lideranças da empresa em todas as etapas.

Algumas deficiências na gestão de competências gerenciais foram detectadas nas empresas (MOHRMAN \& WORLEY, 2009), uma vez que seus dirigentes, em certa medida, centralizam a discussão das ideias com pouca abertura para os departamentos menos envolvidos com o processo de inovação, eles tomam decisões com base na experiência e no feelling com respeito a determinado negócio. Muitas vezes, esses líderes definem suas metas e acompanham os indicadores com pouco alinhamento aos objetivos estratégicos da empresa (Centurión, 2012). No Quadro3, estão relacionadas às etapas do processo de inovação, atendidas de acordo com a teoria estudada.

Quadro 3: Atendimento às Etapas do Processo de Inovação

\begin{tabular}{|c|c|c|c|c|c|c|}
\hline $\begin{array}{c}\text { Empresa/Etapas Processo } \\
\text { Inovação }\end{array}$ & E1 & E2 & E3 & E4 & E5 & E6 \\
\hline Geração de Ideias & A & A & P & P & P & A \\
\hline Conceituação de ideias & A & A & P & P & P & A \\
\hline Seleção de ideias & A & P & P & P & A & A \\
\hline Experimentação & A & A & A & N & N & A \\
\hline Implementação & A & A & P & P & P & A \\
\hline Sustentação & A & A & P & P & P & A \\
\hline Aprendizado & A & P & P & P & P & P \\
\hline
\end{tabular}

Fonte: Elaborado pelos autores (2014).

NotaA-Atende; P-Parcialmente Atende; N-Não Atende.

Nas empresas E3, E4 e E5, o processo de inovação não aconteceu de forma estruturada. Dessas empresas, somente a E3 atende a etapa experimentação conforme apontado pela teoria estudada. As demais atenderam parcialmente ou não atenderam as etapas do processo de inovação. Desse modo, foi considerado como atendimento satisfatório, aquele patamar em que a empresa atendeu, no mínimo, a $70 \%$ das etapas do modelo proposto.

A análise dos dados de inovação desenvolvidos pelas empresas fornecedoras associadas à rede PETROGAS/SE, com base nos resultados, situa a empresa de $\mathrm{P} \& \mathrm{G}$ como agente caracterizado pelo processo de inovação concebido por tipo, grau e funcionalidade inovadora, e se pautando pela existência de uma gestão de inovação em que se identifica certa multifuncionalidade e os processos de inovação mais estruturados se dão pelas exigências das certificações internacionais. Além disso, fica evidente a tensão entre as diferentes concepções de inovação, agravada quando se vê o âmbito interssetorial. Desse modo, sob esse escopo, o setor de $\mathrm{P} \& \mathrm{G}$ é demarcado pela falta de uma gestão 
profissionalizada e limitado apoio à cultura inovadora e ao processo de execução da estratégia de inovação.

Em cada uma das etapas do processo de inovação, as empresas revelam referências à transformação das ideias em ações viáveis de sua inserção no mercado. Assim, a fase de geração de ideias surge pelas necessidades dos clientes e oportunidades tecnológicas; por sua vez, a conceituação das ideias envolve os colaboradores no processo de seu refinamento com fins de aplicação; a seleção de ideias realça os critérios para sua escolha e comunicação em termos de desenvolvimento da inovação; a experimentação é efetivada a partir da seleção de protótipos ou testes para avaliar a funcionalidade do produto; a comercialização e a difusão da inovação, pouco estruturadas no setor, revelam os motivos que levam seus clientes a aceitarem os novos produtos, serviços ou processos. A etapa de sustentação discute o suporte aos clientes após o lançamento da inovação no mercado; e, finalmente, o aprendizado, como a menos praticado, exige esforço reflexivo por parte dos gestores e empregados, visando a analisar os acertos e erros de cada etapa para o provimento de ações corretivas e preventivas.

\section{CONSIDERAÇÕES FINAIS}

O objetivo geral deste estudo consistiu em descrever como ocorre o processo de inovação de empresas fornecedoras associadas à rede PETROGAS/SE, sob a ótica dos seus dirigentes. Para tanto, foi proposto um estudo fundamentado nos modelos de processo de inovação de Tidd, Bessant e Pavitt (2005) e Desouza et al. (2009). O resultado gerado com a aproximação desses modelos teóricos teve como consequência uma proposta que contempla sete etapas de um processo de inovação, evidenciando a trajetória de uma ideia desde o seu surgimento até a sua transformação em algum produto, serviço ou processo inovador. Tal modelo serve de base teórica para um estudo empírico realizado junto aos dirigentes de seis empresas fornecedoras associadas à rede PETROGRAS/SE, reconhecidas como inovadoras, com o propósito de facilitar a descrição dos seus processos de inovação.

Dessa forma, por meio da análise teórica e dos dados empíricos levantados foram realizadas algumas considerações de forma a responder à pergunta norteadora deste estudo: como ocorre o processo de inovação de empresas fornecedoras associadas à rede PETROGAS/SE, na perspectiva de seus dirigentes? 
No que diz respeito às características gerais do processo de inovação das empresas-alvo do estudo, todos os dirigentes das seis empresas pesquisadas apresentaram certa expertise tecnológica relativa ao setor de $\mathrm{P} \& \mathrm{G}$, o que facilita a geração de inovações multifuncionais (produto, processos e serviços) e, por consequência, explica o reconhecimento institucional que vêm recebendo nos âmbitos local, nacional e internacional.

As inovações observadas no estudo são, em sua maioria $(70 \%)$ incrementais. Porém, nas empresas com processos mais estruturados, há certo predomínio de ações mais radicais. Tal fato pode ser decorrente dos riscos inerentes e do custo alto dessas inovações, exigindo dos gestores maior aprimoramento de suas habilidades tecnológicas e gerenciais para sua condução eficaz.

Foi constatado que a gestão do processo de inovação ainda ocorre de acordo com necessidades circunstanciais da empresa e com base na intuição e experiência dos dirigentes. Além disso, menos de um terço dos entrevistados demonstra limitado conhecimento a respeito da temática inovação, pois não conseguirem reconhecer o quanto estavam inovando ou por acreditarem que não é possível gerir uma prática da inovação no contexto do seu empreendimento.

É recomendável, portanto, que tais deficiências sejam mitigadas de forma a melhorar o desempenho das atividades inovadoras e dos resultados finais. A participação de gestores em um programa de qualificação centrado na aprendizagem tecnológica, no desenvolvimento de competências gerenciais e na capacitação inovadora pode levar algumas empresas a atingirem, ao longo do tempo, uma performance significativa de inovação em estágio semelhante ao nível de empresas líderes do setor de $\mathrm{P} \& \mathrm{G}$, inclusive com impactos positivos no incremento de seus índices de produtividade e consequente rentabilidade econômica.

As três empresas pesquisadas que possuem um sistema de gestão integrada ou que são certificadas de acordo com alguma norma ISO revelam maior facilidade para gerir seu processo de inovação, uma vez que esse sistema lhes auxilia na gestão articulada de suas rotinas. Nesse sentido, a concepção de um sistema integrado de gestão permitiria a materialização de ideias em práticas que garantem o surgimento das soluções inovadoras de modo compartilhado, como se fosse a constituição de um, tipo de ecossistema empreendedor com características autóctones da região e do setor, administrado com disciplina e de forma articulada entre os stakeholders.

Quanto à identificação e descrição das etapas do processo de inovação, os resultados indicaram que as empresas possuem um processo de inovação composto pelas sete etapas investigadas. A depender das condições estruturais e financeiras e do estilo de liderança adotado, algumas etapas possuem maior aderência ao modelo teórico adotado neste estudo, a exemplo da geração, conceituação e seleção das ideias, bem como a fase de experimentação, porém ainda com limitações de registro e 
alinhamento estratégico. Por outro lado, existem etapas identificadas que possuem lacunas, a exemplo da implementação, sustentação e aprendizado que, de forma geral, necessitam de certa coordenação e supervisão para o melhor atendimento das necessidades do mercado e sinalização de resultados satisfatórios para a própria empresa.

Um aspecto revelador desse estudo foi evidenciado pela trajetória de empresas de $\mathrm{P} \& \mathrm{G}$ no sentido de gerarem soluções inovadoras, pois por meio da descrição do processo de inovação de cada empresa, foi percebido como elas se organizam, interagem e gerenciam suas ações em prol da inovação.

Esse estudo também permite identificar que as empresas não detentoras de um processo estruturado de inovação apresentam dificuldades significativas para gerar outras formas de inovação, além de não conseguirem repeti-las com frequência. Sendo assim, os resultados indicam que, dentre as empresas de $\mathrm{P} \& \mathrm{G}$ estudadas, somente três (50\%) possuem um processo de inovação mais elaborado, mesmo com algumas limitações gerenciais e estruturais. Também foi visto que as demais empresas não dispõem de um processo sistematizado de inovação, e sim composto de algumas etapas que se comunicam de forma limitada.

Dessa forma, uma revisão sistematizada de todo o processo de inovação em empresas do setor de $P \& G$ pode ser útil para ampliar suas possibilidades de inovação e lhes auxiliar na busca por obtenção de vantagem competitiva. Para tal, faz-se necessária a integração do processo de inovação a alguns pilares fundamentais: o desenvolvimento da cultura que garanta uma liderança pró-inovação, direcionada à estratégia da empresa e à formação de parcerias.

Também se sugere que os dirigentes da área de $P \& G$ se empenhem, com suporte de treinamentos e capacitações, no esforço por aprimorar as competências gerenciais e estratégicas chave, no intuito de serem facilitadores de comportamentos inovadores e gestores mais efetivos do processo de inovação nas empresa integradas este tipo de rede de negócios, conforme orientação de Mohrman \&Worley (2009).

Além das empresas, outros agentes como as IES, os formuladores de políticas públicas, os centros de pesquisa e as instituições financeiras têm sua responsabilidade e papel fundamental para o desenvolvimento de ambiente inovador neste tipo de comunidade de prática tecnologicamente especializada. Diante disso, faz-se necessária uma maior integração e discussão entre esses players na busca por convergência de ideias, compartilhamento de problemas e soluções e definição de ações institucionais para que o processo estruturado de inovação seja de fato interativo e alcance resultados positivos para o desenvolvimento em esferas múltiplas do setor de $\mathrm{P} \& \mathrm{G}$ e seus coprodutores. 
A limitação reconhecida na literatura estudada se refere à carência de modelos voltados para processos de inovação testados e elaborados para a realidade socioeconômica de empresas brasileiras, pois os modelos de Tidd, Bessant e Pavitt (2005) e de Desouza et al. (2009) são originários de empresas de países desenvolvidos da Europa e da América do Norte, em organizações de vários tipos e tamanhos, porém dispondo de determinadas características diferentes da realidade de negócios vigente no Brasil.

Logo, para superar essa limitação, recomenda-se que pesquisadores desenvolvam, a partir de estudos sobre o processo de inovação de empresas brasileiras, sistemas de controle contendo indicadores adaptáveis a tais organizações, de forma que sejam contemplados aspectos relacionados à liderança, à cultura, às formas de interações e aos ambientes interno e externo.

No tocante à proposta de um modelo de estudo como contribuição teórica baseado nos trabalhos de Tidd, Bessant e Pavitt, (2005) e de Desouza et al., (2009), o intuito do estudo foi facilitar a identificação e descrição de como ocorre um processo de inovação em MPME, a partir da geração e avaliação das ideias até o lançamento no mercado. Nesse sentido, foi realizada uma hibridação desses modelos, o que poderá ser rediscutido com profundidade em trabalhos futuros.

O estudo também pode servir de subsídio para melhor entendimento dos dirigentes e demais atores envolvidos nos processos de inovação, pois foram consideradas as semelhanças e diferenças dentre as MPME estudadas, as percepções sobre os acertos com respeito às boas práticas recomendadas pela literatura e alguns modelos de gestão inovadores observados nas próprias empresas.

A reflexão desses agentes envolvidos com o desenvolvimento nas organizações sobre fatores que favorecem e limitam a geração de novidades pode facilitar a implementação de políticas públicas efetivas na dinamização de atividades inovadoras em setores tais como P\&G, biotecnologia, eletrotécnica, entre outros.

Os resultados da pesquisa vão além dos resultados do PINTEC (2008), pois as empresas sergipanas consideradas inovadoras da área de $\mathrm{P} \& \mathrm{G}$ não participaram de sua amostra, apesar de contribuírem para a posição de destaque do Estado de Sergipe como o quinto maior produtor de petróleo e gás do Brasil no ano 2011. 


\section{REFERÊNCIAS}

Abernathy, W. J.,\& Clark, K. B. (1985). Innovation: mapping the winds of creative destruction. Research Policy. North Holland, 14, 3-22.

Anuário Estatístico Brasileiro do Petróleo, Gás Natural e Biocombustíveis.(2011). Agência Nacional do Petróleo, Gás Natural e Biocombustíveis. Recuperado em 08 dezembro, 2012, de http://www.anp.gov.br/?pg=8240\#Se_o_1

Barbieri, J. C.,\& Álvares, A. C. (2003). Inovações nas Organizações Empresariais. In J. C. Barbieri (Org.) Organizações Inovadoras: estudos e casos brasileiros. Rio de Janeiro: Editora FGV.

Bardin, L. (2004).Análise de Conteúdo.3. ed. Lisboa: Edições 70.

Berglund, A.(2007).Assessing the Innovation Process of SMEs.(Licentiate Thesis). Luleå University of Technology, Sweden.

Caetano, M., Kurumoro, S. J., Amaral, C. D. (2012). Estratégia de integração entre tecnologia e produto: identificação de atividades críticas no processo de inovação. RAI, Revista de Administração e Inovação, São Paulo, 9(2), 123-146- abr./jun.

Centurión, W. C.(2012). Processo de inovação de empresas fornecedoras associadas à rede

Petrogas/SE: um estudo multicascos. 202f. Dissertação de Mestrado em Administração. Universidade Federal de Pernambuco, Recife.

Cooper, R. G. (1998).Product Leadership: Creating and Launching Superior New Products. Reading, Mass: Perseus Books (formerly Addison-Wesley).

Creswell, J. W. (2007).Projeto de Pesquisa: método qualitativo, quantitativo e misto. 2.ed. Porto Alegre: Artmed/Bookman.

Desouza, K. C.,Dombrowski, C., Awazu, Y.,Baloh, P.,Papagari, S., Jha, S., \& Kim, J.(2009).Crafting organizational innovation processes. Innovation: management, policy \& practice.11(1), 6-33.

Flick, U. (2004).Pesquisa Qualitativa.Porto Alegre:Bookman.

Gaskell, G., \& Bauer, M. W. (2005).Para uma prestação de contas pública: além da amostra, da fidedignidade e da validade. In BAUER, M. W.,\&GASKELL, G. (Ed.). Pesquisa qualitativa com texto, imagem e som: um manual prático. 4. ed. Petrópolis-RJ: Vozes.

Índice de Inovação Global - ING. (2011). Recuperado em15 dezembro, 2011, dehttp://www.globalinnovationindex.org

Instituto Nacional de Propriedade Industrial - INPI.(2011). Recuperado em 15 de setembro, 2011, de http://www.inpi.gov.br/index.php/patente/busca.

Johnson, S. (2010). Where good ideias come from: the natural history of innovation. New York-USA: Riverheads Books.

Junarsin, E. (2009). Managing Discontinuous Innovation. International Management Review, 5 (1). 
Kato, E. M., Gobara, C., Rossoni, L.,\& Cunha, S. K. (2008). Padrões de cooperação tecnológica entre setores na indústria brasileira: uma análise quantitativa dos dados da PINTEC 2001-2003. Revista de Administração e Inovação, São Paulo, 5(3), 126-140.

McAdam, R., \&Armstrong, G. (2001). A symbiosis of quality and innovation in SMEs: a multiple case study analysis. Managerial Auditing Journal, 16(7), 394-399.

Merriam, S. B. (1998). Qualitative research and case study applications in education: revised and expanded from case study research in education.2.ed. São Francisco-CA: Jossey-Bass Education Series and The Josey-Bass Higher Education Series.

Mohrman, S. A., \& Worley, C. G. (2009). Dealing with rough times: a capabilities development approach to surviving and thriving. Human Resource Management, May-

June 2009, 48 (3) 433-445. Published online in Wiley Inter Science

(www.interscience.wiley.com).

Oliveira, M. R.G, Cavalcanti. A. M.; Paiva Júnior, F. G. Marques, D. B. (2014).Mensurando

a inovação por meio do grau de inovação setorial e do característico setorial de inovação.

Revista de Administração e Inovação. V.11, n.1.

Organization for Economic Cooperation an Development,\& Financiadora de Estudos e Projetos (OECD).(2005). Manual de Oslo: Diretrizes para coleta e interpretação de dados sobre inovação. Brasília-DF.

Ormerod, P., \&Rosewell, B. (2009).Innovation, diffusion and agglomeration. Economics of Innovation and New Technology, 18(7), 695-706.

Paiva Júnior, F. G.,Leão, A. L. M. S.,\&Mello, S.C. B. (2011) Validade e Confiabilidade na Pesquisa Qualitativa em Administração. Revista de Ciências da Administração, 13 (31), maio-agosto, 190- 209.

Pereira, M. F., Grapeggia, M., Emmendoerfer, M. L. \& Três, D. L. (2009). Fatores de inovação para a sobrevivência das micro e pequenas empresas no Brasil. Revista de Administração e Inovação, São Paulo, 6 (1), 50-65.

Pesquisa de Inovação Tecnológica - PINTEC. (2008). Instituto Brasileiro de Geografia e Estatística $I B G E$.

Rajegopal, S. (2012). Portfolio Management: How to Innovate and Invest in Successful Projects. Palgrave Macmillan.

Rogers, E. M. (2003). Diffusion of Innovations. New York: Free Press.

Santos, D. F. L., Basso, L. F. C.,\&Kimura, H. (2012). A estrutura da capacidade de inovar das empresas brasileiras: uma proposta de construto. Revista de Administração e Inovação, São Paulo, 9(3), jul/set, 103-128.

Scherer, F. O.,\&Carlomagno, M. S. (2009). Gestão da inovação na prática: como aplicar conceitos $e$ ferramentas para alavancar a inovação. São Paulo: Atlas.

Revista de Administração e Inovação, São Paulo, v. 12, n.1, p.24-51, jan./mar. 2015. 
Secretaria de Estado do Planejamento, Orçamento e Gestão - SEPLAG.(2011). Brazil Confidential. Recuperado em 20 novembro, 2011, dehttp://novo.seplag.se.gov.br/noticias/956-sergipe-e-destaqueno-jornal-ingles-financial-times

Silva, M. E, Sousa, I. G.,\&Freitas, L. S. (2012). Processo de inovação: um estudo no setor moveleiro de Campina Grande - PB. Revista de Administração e Inovação, São Paulo, 9(1), jan./mar, 257-279.

Sousa, A. A.,\& Oliveira, A. L. N. (2012).Inovação tecnológica nas empresas fornecedoras de bens $e$ serviços da cadeia de petróleo e gás natural de Sergipe. In.: Sousa, A. A. et al. (Orgs). Redes de Cooperação como Indutoras da Inovação: formação de um ambiente inovador na cadeia de petróleo, gás e energia de Sergipe, São Cristóvão: UFS.

Teece, D. J. (1986).Profiting from technological innovation: implications for integration, collaboration, licensing and public policy. Research Policy. North-Holland, jun. 1986,15, 285-305.

Tidd, J., Bessant, J., \&Pavitt, K. (2005). Managing Innovation: integrating technological, market and organizational change. 4.ed. John Wiley\& Sons, Ltd: Chicester.

Tigre, P. B. (2006). Gestão da Inovação: a economia da tecnologia no Brasil. Rio de Janeiro: Elsevier.

Vicenti, T., \& Machado, D. P. N. (2010). Ambiente de inovação em empresas de software: estudo das diferenças entre empresa-mãe e seus spin offs. Revista Eletrônica de Administração, 16(1) ed. 65.

Von Oetinger, B. (2005). Nurturing the new: Patterns for innovation. Journal of Business Strategy, 26(2), p.29-36. 


\title{
THE TECHNOLOGICAL INNOVATION PROCESS OF SUPPLIER FIRMS AFFILIATED WITH THE PETROGAS/SE NETWORK
}

\begin{abstract}
Technological innovation has aroused the interest of managers of micro, small and large companies, because it is a contemporary theme that accelerates sustainable processes in several areas of management, mainly recognized by governments, businesses, universities and research centers as indispensable in contemporary economy. On the other hand, few organizations have structured systems and processes of innovation, since the ideas do not become real products and services, and many innovation actions are isolated and ineffective and are not aligned with the company's strategic objectives. Through qualitative research, the study describes the innovation process of six suppliers associated with the PETROGAS/SE network, from its leaders' perspectives. Interviews were analyzed using content analysis, and the results revealed that the management of the innovation process is based on the managers' tacit knowledge. Companies with quality certification tend to manage their innovation process in a more structured way, and some steps in this process have greater adherence to studied theory.
\end{abstract}

Data do recebimento do artigo: 15/01/2014

Data do aceite de publicação: 15/10/2014

Revista de Administração e Inovação, São Paulo, v. 12, n.1, p.24-51, jan./mar. 2015. 